\title{
Harmful Impact of ZnS Nanoparticles on Daphnia sp. in the Western Part (Districts of Bankura and Purulia) of West Bengal, India
}

\author{
Baibaswata Bhattacharjee, ${ }^{1}$ Nilanjana Chatterjee, ${ }^{2}$ and Chung-Hsin $\mathrm{Lu}^{3}$ \\ ${ }^{1}$ Department of Physics, Ramananda College, Bishnupur, Bankura, West Bengal 722 122, India \\ ${ }^{2}$ Department of Zoology, Ramananda College, Bishnupur, Bankura, West Bengal 722 122, India \\ ${ }^{3}$ Department of Chemical Engineering, National Taiwan University, Taipei, Taiwan \\ Correspondence should be addressed to Baibaswata Bhattacharjee; baib23@gmail.com
}

Received 24 June 2013; Accepted 7 August 2013

Academic Editors: S. Misra, X. Tian, and Z. Xu

Copyright (c) 2013 Baibaswata Bhattacharjee et al. This is an open access article distributed under the Creative Commons Attribution License, which permits unrestricted use, distribution, and reproduction in any medium, provided the original work is properly cited.

\begin{abstract}
ZnS nanoparticles of different sizes are synthesized employing a simple wet chemical method. These nanoparticles are used to study their impact on the Daphnia sp. through traditional toxicity tests. The percentage of mortality is found to increase initially with increasing nanoparticle concentration or exposure time and is finally found to saturate for higher concentrations or exposure times. Mortality is found to be higher for smaller particles. Hopping frequency and heart rate are also found to increase with increasing nanoparticle exposure time for a fixed nanoparticle concentration. These observations can be attributed to the enhanced surface photooxidation property of the $\mathrm{ZnS}$ nanoparticles. Thus the present study will help people to understand the hitherto unknown harmful impact of ZnS nanoparticles on aquatic organisms in the western part of West Bengal (Bankura and Purulia districts), India.
\end{abstract}

\section{Introduction}

Nanoparticles $(1-100 \mathrm{~nm})$ comprise the latest technological advances designed for various applications [1]. Many nanoparticle compounds occur naturally and are used in many vital life processes [1]. Because of their very small size, they have chemical properties that differ from those of their bulk counterparts [2]. As the size of the particle decreases, the percentage of atoms exposed on the surface increases. Because of their increased reactivity, the interaction of the particle with its environment also changes. The change in reactivity increases the potential of nanoparticles for use in industry and pharmaceuticals [2], but this also is the reason for environmental concern.

Recently, nanoparticles have come under scrutiny for their potential to cause environmental damage $[3,4]$. Because of their increased reactivity, nanoparticles can be detrimental to the environment. Therefore, it is very important to understand the potential impacts of nanoparticles upon environments. The increased production of nanoparticles is making it more likely that such materials will end up in watercourses, either as medical or industrial waste, or when used as ecological tools, with unknown consequences for aquatic life. Therefore, it is gradually becoming very important to identify the most appropriate route of nanotechnology that will preserve the aquatic environment while also advancing industrial technology.

Recent studies [5-9] have revealed some of the detrimental effects of different nanoparticles on animals. Inorganic nanoparticles such as $\mathrm{TiO}_{2}, \mathrm{SiO}_{2}$, and $\mathrm{ZnO}$ had a toxic effect on bacteria, and the presence of light was a significant factor increasing the toxicity [5]. Titanium dioxide can have undesirable effects when inhaled and has a damaging impact on rodents [6]. At the one-year mark, rats continued to exhibit adverse effects even with an initial exposure of only 13 weeks [6]. Warheit et al. [7] found that exposure to carbon 
nanoparticles caused inflammation and cell injury in rats. Though fullerenes are found to have only little impact on the soil microbial community and function, based on soil respiration, soil enzyme activity, and changes in community structure [8], yet bacterial cell walls show a physiological adaptation to the presence of fullerenes and they show a response in lipid composition and membrane phase behavior [9].

Ecotoxicological studies show that nanoparticles are also toxic to aquatic organisms, both unicellular (e.g., bacteria or protozoa) and animals (e.g., Daphnia or fish). Carbon nanotubes (CNT) induced a dose-dependent growth inhibition in a protozoan [10] and were found to be a respiratory toxicant in rainbow trout [11]. CNT coated with lipids were readily taken up by Daphnia magna and they modified the solubility of the CNT through digestion of the lipid coating [12]. Acute toxicity was only observed at the highest concentration. Fullerenes were shown to be detrimental in aquatic environments [13-18]. They caused oxidative damage in largemouth bass (Micropterus salmoides) [13] by acting through the same mechanism of action found to be beneficial for their use in drug delivery [14]. Fullerenes are able to travel to the brain, bind with lipids, and cause the production of oxidative stress compounds when fish are exposed to concentrations of only $1 \mathrm{ppm}$ [13]. Fullerenes $\left(\mathrm{C}_{60}\right)$ interact adversely with several aquatic organisms, for example, bacteria $[15,16]$, zooplankton and fish $[13,17,18]$. Exposure to $\mathrm{C}_{60}$ causes an increase in mortality and shows higher levels of toxicity at lower concentrations for Daphnia magna [19].

The exposure of metal nanoparticles to the aquatic environment has also detrimental effect towards the aquatic biota [20]. The cells of bacteria are found to be damaged in the presence of nanosilver, finally resulting in death of the organisms [21]. The interaction of nanosilver with the cells is found to be size dependent [22] and seems to depend also on the shape of the particles [23]. Nanosilver appears to be significantly more toxic than $\mathrm{Ag}^{+}$-ions towards E. coli [24]. It is found that nano-sized copper particles affect fish gills of Zebra fish (Danio rerio) through a different and as-yetunknown mechanism than dissolved copper ions do [25]. The results suggested that copper nanoparticles are more lethal than carbon or titanium dioxide $\left(\mathrm{TiO}_{2}\right)$ nanoparticles.

Bulk $\mathrm{TiO}_{2}$ is considered to have no health effects on aquatic organisms but exposure to $\mathrm{TiO}_{2}$ nanoparticles causes an increase in mortality with an increase in nanoparticle concentration in Daphnia magna [19]. Exposure of $\mathrm{TiO}_{2}$ nanoparticles to rainbow trout (Oncorhynchus mykiss) [26] results respiratory problems and other sublethal effects in the fish.

Daphnia organisms are bioindicators and an extremely important member in aquatic ecosystem. Daphnia are crustaceans, commonly found in ponds and lakes and widely sold as live fish food. They feed by filtering minute particles, such as bacteria and algae, from the fresh water in which they live. They interact with large portions of the environment and therefore have a greater potential to be affected by ingestion of pollutant particulates compared to that of other aquatic organisms. Nanoparticles have the potential to be taken in during filtration and could interfere with the physiology or the feeding ability of the animal.
In the districts like Bankura and Purulia, some of the industries, such as medical hubs, are cropping up without proper site for sewage disposal containing predominantly sulphide nanoparticles. $\mathrm{ZnS}$ is one of such material that can be found in the waste of cosmetic, pharmaceutical and rubber industries. It has also the property of photooxidation. Apart from the common effect on the environment for its nanoparticle nature, $\mathrm{ZnS}$ nanoparticles may also have some passive effects by disturbing the dissolved oxygen content of water due to its surface photooxidation, which can be more pronounced for nanoparticles having greater surface area. Though a number of reports are available $[12,18,19]$ on the adverse effect of $\mathrm{TiO}_{2}$ or $\mathrm{C}_{60}$ nanoparticles and CNT on the Daphnia sp., studies investigating impacts of sulphide nanoparticles on Daphnia sp. are very few [27, 28]. Any systematic study on the adverse effect of $\mathrm{ZnS}$ nanoparticles on the Daphnia sp. as well as on the aquatic environment is yet to be done. The present study is expected to fill this lacuna and will help to understand the impact of $\mathrm{ZnS}$ nanoparticles on the aquatic organisms in these localities that is hitherto unknown. This will also help people to restore the balance in local aquatic ecosystem.

\section{Experimental}

A simple wet chemical technique is employed to obtain $\mathrm{ZnS}$ nanoparticles. A solution of $\mathrm{Zn}\left(\mathrm{NO}_{3}\right)_{2} \cdot 6 \mathrm{H}_{2} \mathrm{O}$ (purified, Merck India) in 2-propanol $\left(\mathrm{CH}_{3}\right)_{2} \mathrm{CHOH}$ (GR, Merck India) dried over activated molecular sieve zeolite $4 \mathrm{~A}$ and distilled water is used as the zinc precursor. The volume ratio of water and alcohol is 2-propanol: $\mathrm{H}_{2} \mathrm{O}=1: 5$. This value is maintained throughout to prepare the solution. This solution is stirred for 2 hours. In another solution, sodium sulfide $\left(\mathrm{Na}_{2} \mathrm{~S}\right)$ (purified, Merck India) is dissolved in distilled water and also stirred for 2 hours. It is used as the sulfur precursor. The precursors are so chosen that the molar ratio of zinc and sulfur was maintained as $\mathrm{Zn}: \mathrm{S}=1: 1$ to obtain the required stoichiometry in the derived zinc sulfide. After stirring, $\mathrm{Na}_{2} \mathrm{~S}$ solution is quickly injected to the solution containing $\mathrm{Zn}$ precursor. Immediate formation of colloids containing $\mathrm{ZnS}$ nanoparticles is observed. The particle size is controlled by variation of the reaction temperature. Once the reaction is completed, the solution is kept at room temperature. The precipitates are centrifuged, washed with deionized water, ethanol, and acetone for several times it dried at $70^{\circ} \mathrm{C}$ in a vacuum oven, and kept in vacuum for further use.

Transmission electron microscopy (TEM) is performed using a Hitachi H-7100 microscope operated at the voltage of $100 \mathrm{kV}$. Powder dispersed in ethanol is carefully placed on the carbon coated $\mathrm{Cu}$ grid for TEM study. A particle size analyzer (Nano-S, Malven, Worcedtershire, UK) is used to measure the size distribution histogram using methanol as the solvent. An $\mathrm{X}$-ray diffraction (XRD) study is performed in a MAC M03 XHF diffractometer using $\mathrm{Ni}$ filtered $\mathrm{Cu} \mathrm{K}_{\alpha}$ radiation $(\lambda=$ $0.154056 \mathrm{~nm}$ ) as $\mathrm{X}$-ray source at $40 \mathrm{kV}, 30 \mathrm{~mA}$. The $\theta / 2 \theta$ scans are carried out at a scanning speed of $2^{\circ} / \mathrm{min}$ in the $2 \theta$ range of $20^{\circ}$ to $60^{\circ}$. X-ray photoelectron spectroscopic measurements (XPS) are done using a commercial VG Microtech (MT-500) 


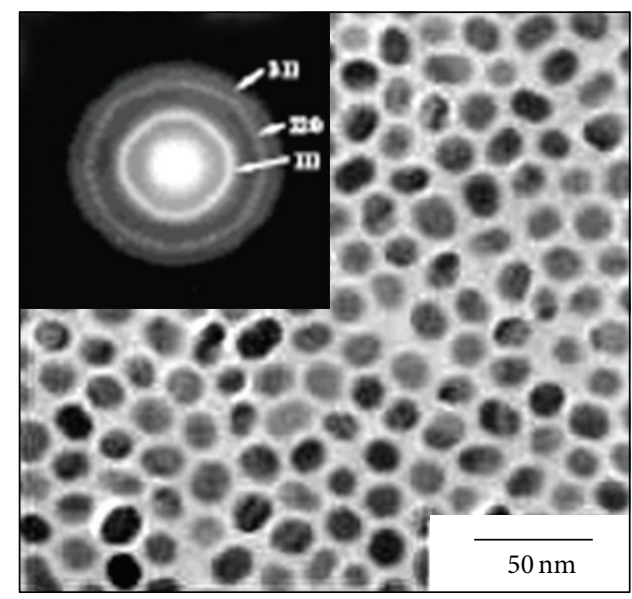

(a)

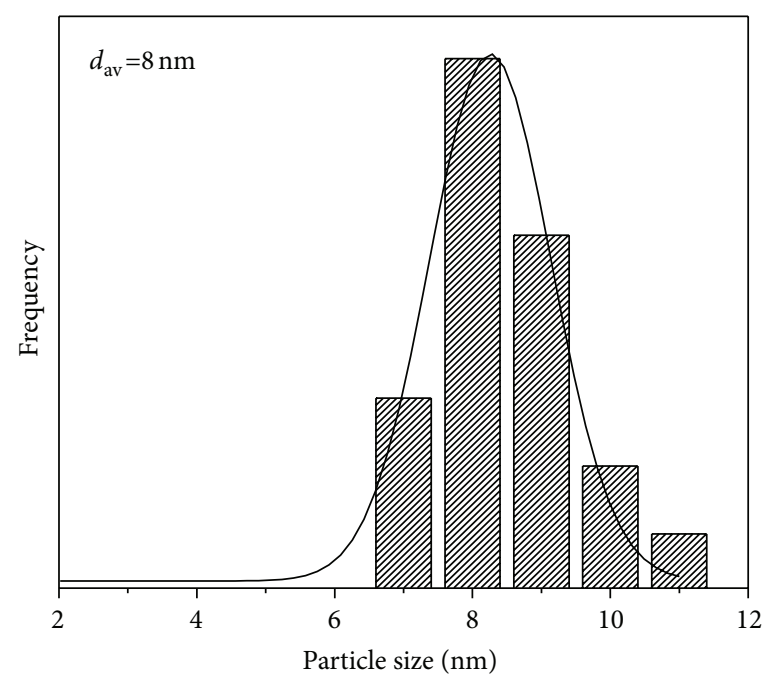

(b)

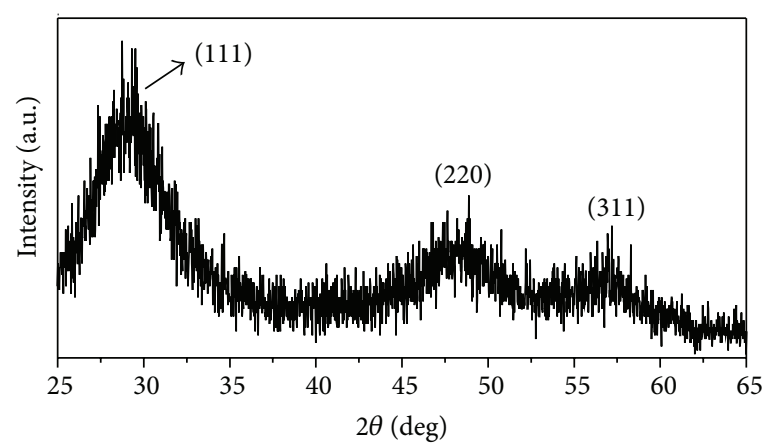

(c)

FIGURE 1: (a) Transmission electron micrograph (TEM) of representative ZnS nanoparticles and (inset) the corresponding diffraction pattern. (b) Particle size analysis (PSA) data of the same representative sample. (c) X-ray diffraction (XRD) pattern of the same representative sample.

XPS machine using $\mathrm{Al} \mathrm{K}_{\alpha}$ radiation. A properly calibrated electronic laboratory meter with a probe is used to measure the dissolved oxygen content in water. A calibration curve is drawn and used to obtain the dissolved oxygen content in water under different experimental conditions. Plankton counting cells are used to determine the mortality. Daphnia sp. movements under different experimental conditions are recorded in a movie camera for a stretch of 10 minutes in each case. These films are then used to determine the average heart rate and hopping frequency of the zooplankton under those experimental conditions.

Daphnia sp. is collected from the water of Lal-bandh (ancient water body) at Bishnupur $\left(23.08^{\circ} \mathrm{N}, 87.32^{\circ} \mathrm{E}\right)$, Bankura district, and Saheb-bandh (ancient water body), at Purulia $\left(23.37^{\circ} \mathrm{N}, 86.43^{\circ} \mathrm{E}\right)$, Purulia district. They are kept in watertight containers containing tap water that has been allowed to stand for a few days. A good supply of necessary oxygen is provided by using a large shallow tank to ensure that a large surface area of water is exposed to the air. Daphnia sp. cultures are maintained at $15^{\circ} \mathrm{C}$ to ensure rapid growth of the colony. The colony of Daphnia sp. is fed on a few drops of a suspension of fresh yeast and of egg-yolk medium (made by blending a hard-boiled egg in $500 \mathrm{~cm}^{3}$ of water). Small, regular supplies of food, only sufficient to cause the water to turn just faintly cloudy, are provided. After every three days, the Daphnia sp. is filtered out and placed in fresh water. Daphnia sp. is not fed for the duration of the experiment.

Daphnia sp. is exposed to ten concentrations $(1,2,3,4$, $5,6,7,8,9$, and $10 \mathrm{ppm}$ ) of the $\mathrm{ZnS}$ nanoparticles of different sizes ( $3 \mathrm{~nm}, 7 \mathrm{~nm}, 12 \mathrm{~nm}$, and $20 \mathrm{~nm}$ ) for 30 minutes. Trials are conducted at various concentrations to observe effects and to obtain the concentration that caused maximum mortality. After this range is achieved, trials are repeated to observe the effect of time of exposure of ZnS nanoparticles on Daphnia sp. Impact of ZnS nanoparticles on Daphnia sp. is characterized through traditional toxicity test, namely, (a) determination of mortality, (b) determination of hopping frequency and (c) measurement of heart rate.

\section{Results}

3.1. Microstructures and Composition of ZnS Nanoparticles. Figure 1(a) shows the TEM of $\mathrm{ZnS}$ nanoparticles with the corresponding diffraction pattern in inset. Presence of fine $\mathrm{ZnS}$ nanoparticles is clearly visible in the TEM picture (Figure 1(a)). The diffraction pattern of the sample consists 


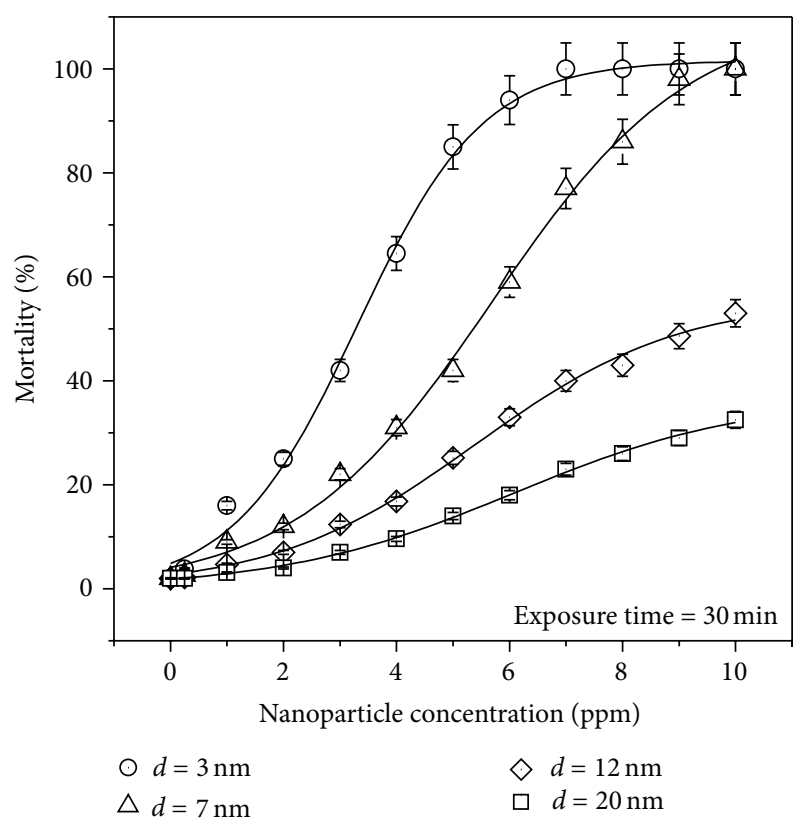

FIGURE 2: Variation of the percentage of mortality with increasing nanoparticle concentration for $\mathrm{ZnS}$ nanoparticles with different particle sizes $(3 \mathrm{~nm}, 7 \mathrm{~nm}, 12 \mathrm{~nm}$, and $20 \mathrm{~nm})$ and 30 minutes of exposure time.

of a central halo with concentric broad rings. The rings correspond to the reflections from (111), (220), and (311) planes confirming the cubic crystallographic structure of the $\mathrm{ZnS}$ nanoparticles. The average size $\left(d_{\mathrm{av}}\right)$ of the nanocrystallites determined from TEM is around $7 \mathrm{~nm}( \pm 0.5 \mathrm{~nm})$. Particle size analysis (PSA) data shows (Figure 1(b)) narrow size distribution of the particles with $d_{\mathrm{av}} 8 \mathrm{~nm}$. This result is consistent with the TEM result.

Figure 1(c) illustrates the XRD pattern of $\mathrm{ZnS}$ nanoparticles. The pattern shows peak from (111), (220), and (311) planes, indicating the formation of cubic phase, in agreement with the electron diffraction results. Broadening of the XRD peaks can be attributed to the small size of the $\mathrm{ZnS}$ nanoparticles present in the sample. The crystallite size is obtained as $7.02 \mathrm{~nm}$ from the XRD data using the Debye equation. This value tallies well with the TEM and PSA results as mentioned earlier.

The chemical compositions of $\mathrm{ZnS}$ nanoparticles are determined by EDX measurements. The $\mathrm{Zn} / \mathrm{S}$ ratio for the samples with different particle sizes is obtained from EDX data. To determine the chemical uniformity of the nanoparticles, EDX measurements are done at different parts of the samples and an average for each sample is obtained. The data clearly reveals almost uniform chemical homogeneity $(\mathrm{Zn} / \mathrm{S}$ ratio $\sim 1)$. The EDX data are further verified performing X-ray photoelectron spectroscopy (XPS). The $\mathrm{Zn} / \mathrm{S}$ ratio calculated from XPS data tallies well with that of EDX data.

\subsection{Traditional Toxicity Test}

3.2.1. Mortality Rate. Percentage of mortality $(m)$ is quantified by the number of individuals dying in every hundred individuals after exposure to nanoparticles. Figure 2 shows

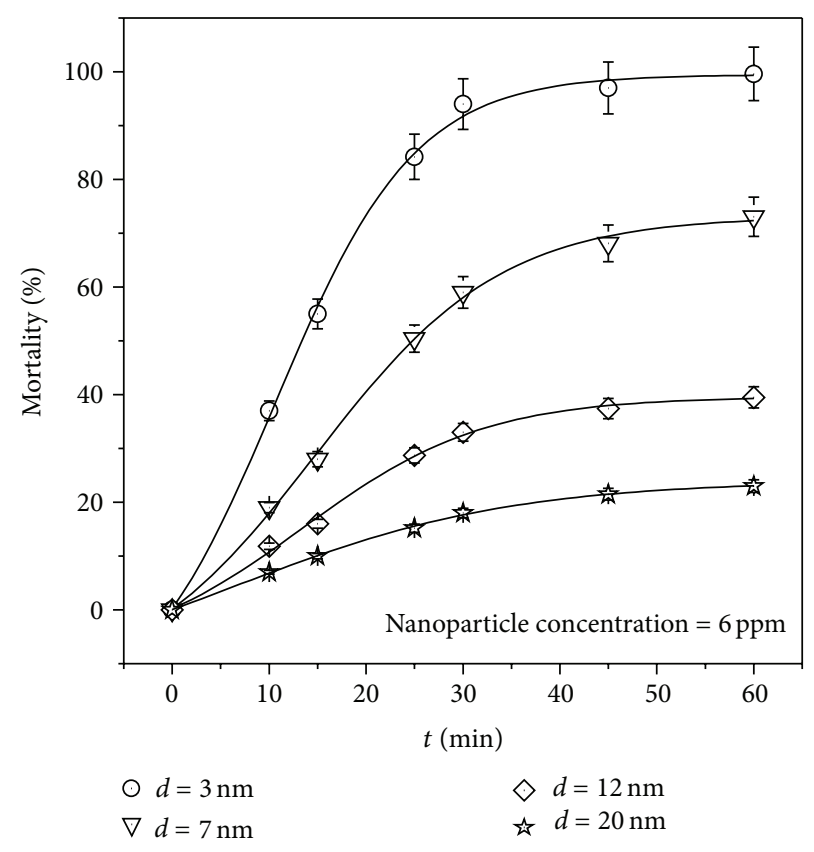

FIGURE 3: Variation of the percentage of mortality with increasing nanoparticle exposure time for $\mathrm{ZnS}$ nanoparticles with different particle sizes $(3 \mathrm{~nm}, 7 \mathrm{~nm}, 12 \mathrm{~nm}$, and $20 \mathrm{~nm})$ and nanoparticle concentration of $6 \mathrm{ppm}$.

the impact of increasing nanoparticle concentration on the mortality of the Daphnia sp. for 30 minutes of exposure time. It can be seen from the figure that the $m$ value increases with increasing nanoparticle concentration for all sets of nanoparticles having different sizes. For the $\mathrm{ZnS}$ nanoparticles of size $3 \mathrm{~nm}$, the percentage of mortality increases rapidly with increase in $\mathrm{ZnS}$ concentration and reaches nearly $90 \%$ for $\mathrm{ZnS}$ concentration of $6 \mathrm{ppm}$. Beyond this concentration, the percentage of mortality increases very slowly and almost saturates at $98 \%$ for higher $\mathrm{ZnS}$ concentration. For the $\mathrm{ZnS}$ nanoparticles of size $7 \mathrm{~nm}$, the $m$ value also increases rapidly with increase in nanoparticle concentration. But in this case, the $m$ value reaches only nearly $60 \%$ for $6 \mathrm{ppm} \mathrm{ZnS}$ concentration, showing much less value of $m$ when compared to that with $\mathrm{ZnS}$ nanoparticles having $3 \mathrm{~nm}$ sizes. Beyond the concentration of $6 \mathrm{ppm}$, the $m$ value increases at the same rate and touches the $m$ value for particle size of $3 \mathrm{~nm}$ at the concentration of $10 \mathrm{ppm}$. For the $\mathrm{ZnS}$ nanoparticles of size $12 \mathrm{~nm}$ and $20 \mathrm{~nm}$, the $m$ value is also found to increase but in slower rates and is found to saturate at $42 \%$ and $24 \%$, respectively, for $\mathrm{ZnS}$ concentration of $10 \mathrm{ppm}$.

Figure 3 shows the impact of increasing nanoparticle exposure time on the mortality of the Daphnia sp. for nanoparticle concentration of $6 \mathrm{ppm}$. It can be seen from the figure that the $m$ value increases with increasing exposure time for all sets of nanoparticles having different sizes showing the same qualitative behavior. For the $\mathrm{ZnS}$ nanoparticles of size $3 \mathrm{~nm}$, the percentage of mortality increases rapidly with increase in exposure time and reaches nearly $90 \%$ for exposure time of 30 minutes. Beyond this time, the percentage of mortality almost saturates for higher exposure 


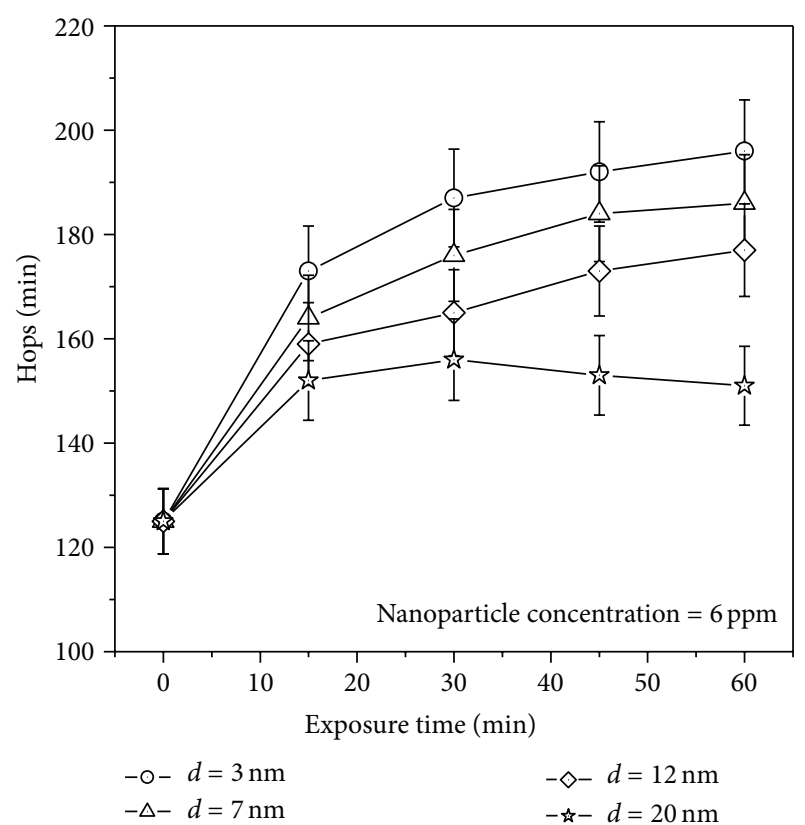

FIGURE 4: Variation of the hopping frequency of Daphnia sp. with increasing nanoparticle exposure time for $\mathrm{ZnS}$ nanoparticles different particle sizes $(3 \mathrm{~nm}, 7 \mathrm{~nm}, 12 \mathrm{~nm}$, and $20 \mathrm{~nm})$ and nanoparticle concentration of $6 \mathrm{ppm}$.

time. For the $\mathrm{ZnS}$ nanoparticles of size $7 \mathrm{~nm}$, the $m$ value also increases rapidly with increase in exposure time and reaches nearly $60 \%$ for 30 minutes of exposure, showing much less value of $m$ when compared to that with $\mathrm{ZnS}$ nanoparticles of size $3 \mathrm{~nm}$. Beyond this time, the percentage of mortality almost saturates for higher exposure time. For $\mathrm{ZnS}$ nanoparticles of size $12 \mathrm{~nm}$ and $20 \mathrm{~nm}$, the $m$ values are also found to increase in slower rates and saturate at comparatively lower $m$ values beyond the exposure time of 30 minutes.

3.2.2. Hopping Frequency. Hopping in Daphnia sp. is exhibited by the downward thrusting of the second antennae below the helmet and then back above. Movement such as hopping rate plays a significant role in aquatic trophic relationships by affecting predation rate. Decreased movement of a zooplankton will diminish the ability of the predator to locate its prey, thereby decreasing predation risk, while irregular movements increase visibility of Daphnia sp. to predators. Figure 4 shows the impact of increasing nanoparticle exposure time on the hopping frequency of the Daphnia sp. for nanoparticle concentration of $6 \mathrm{ppm}$. It can be seen from the figure that the hopping frequency increases with increasing exposure time for all sets of nanoparticles having different sizes. In control condition, the zooplanktons show the hopping frequency of 125 hops/minute in average. For the $\mathrm{ZnS}$ nanoparticles of size $3 \mathrm{~nm}$, the hopping frequency increases rapidly with increase in exposure time and reaches nearly 173 hops/minute for exposure time of 15 minutes. Beyond this time, the hopping frequency increases in a relatively slower rate and almost saturates at 190 hops/minute for exposure time of 45 minutes

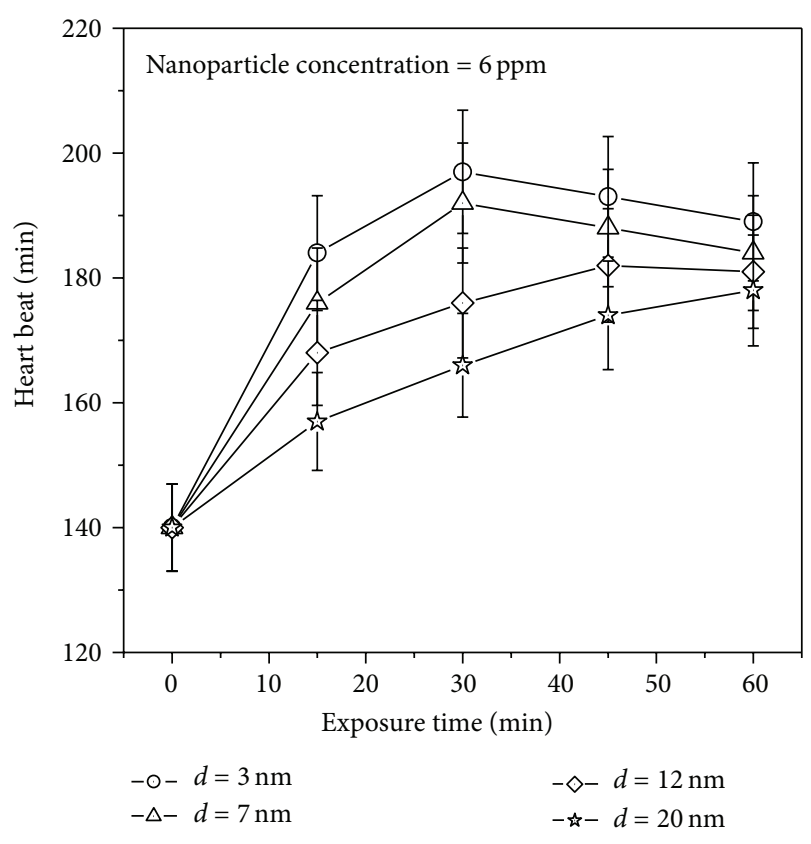

Figure 5: Variation of the heart rate of Daphnia sp. with increasing nanoparticle exposure time for $\mathrm{ZnS}$ nanoparticles with different particle sizes $(3 \mathrm{~nm}, 7 \mathrm{~nm}, 12 \mathrm{~nm}$, and $20 \mathrm{~nm})$ and nanoparticle concentration of $6 \mathrm{ppm}$.

and greater. The change in hopping frequency in the presence of $\mathrm{ZnS}$ nanoparticles in the environment for the nanoparticles of size $7 \mathrm{~nm}, 12 \mathrm{~nm}$, and $20 \mathrm{~nm}$ shows a similar type of behavior as in the case of the nanoparticles of size $3 \mathrm{~nm}$, though it can be noticed that the departure from the value of control condition (125 hops/minute) decreases with increase in the nanoparticle sizes.

3.2.3. Heart Rate. Heart rate is quantified by the number of contractions in heart viewed (heart beat) per minute in the Daphnia sp. Heart rate has been used as an indication of physiological effects in studies on temperature and chemical exposure. It has been suggested that sublethal concentrations of toxicants may change individual physiological behaviors that have long-term effects at the population level. Figure 5 shows the impact of increasing nanoparticle exposure time on the heart rate value of the Daphnia sp. for nanoparticle concentration of $6 \mathrm{ppm}$. It can be seen from the figure that the heart rate increases with increasing exposure time for all sets of nanoparticles having different sizes. In control condition, the zooplanktons show the heart rate of 140 in average. In case of the $\mathrm{ZnS}$ nanoparticles of size $3 \mathrm{~nm}$, the heart rate increases rapidly with increase in exposure time and reaches a peak of nearly 195 for the exposure time of 30 minutes. Beyond this time, the heart rate value goes down and reaches a lower value for exposure time of 60 minutes. For the $\mathrm{ZnS}$ nanoparticles of size $7 \mathrm{~nm}$, the heart rate also increases rapidly with increase in exposure time, reaches a peak for the exposure time of 30 minutes and goes down and for higher exposure time. No such behavior is observed for $\mathrm{ZnS}$ nanoparticles of size $12 \mathrm{~nm}$ and $20 \mathrm{~nm}$, in which the heart rate is found to increase in 
slower rates and saturation values are achieved beyond the exposure time of 30 minutes.

\section{Discussions}

$\mathrm{ZnS}$ nanoparticles themselves are not found to be as harmful as compared to those of $\mathrm{TiO}_{2}$ or $\mathrm{C}_{60}$ [19] when directly ingested by the zooplanktons. But due to the enhanced surface photooxidation property associated to the greater surface area, $\mathrm{ZnS}$ in the nanoparticle form pose serious threat to the aquatic lives by reducing the dissolved oxygen content in the water. The oxygen dissolved in water bodies is crucial for the organisms and creatures living in it. This dissolved oxygen is breathed by fish and zooplankton and is needed by them to survive. As the amount of dissolved oxygen drops below normal levels in water bodies, the water quality is harmed and creatures begin to die off.

In the present study, the dissolved oxygen content in water is measured as $13.2 \mathrm{mg} / \mathrm{L}$ before any nanoparticle is introduced in it. The dissolved oxygen content in water is found to decrease to the values of $11.9 \mathrm{mg} / \mathrm{L}, 9.8 \mathrm{mg} / \mathrm{L}$, $8.9 \mathrm{mg} / \mathrm{L}$, and $7.6 \mathrm{mg} / \mathrm{L}$ for $\mathrm{ZnS}$ nanoparticles of sizes $20 \mathrm{~nm}$, $12 \mathrm{~nm}, 7 \mathrm{~nm}$, and $3 \mathrm{~nm}$, respectively, when exposed for 3 hours in water at a concentration of $10 \mathrm{ppm}$ under the normal sun light. The decrease in the dissolved oxygen content in water can be explained by the instability of $\mathrm{ZnS}$ due to photooxidation. It is an indication of the surface oxidation of the nanoparticles when it was exposed to visible light. This is normal in a humid atmosphere. Lu et al. [29] have studied the photooxidation properties of uncapped CdSe nanoparticles in humid atmosphere using XPS data. A similar study on XPS spectra of $\mathrm{ZnS}$ nanoparticles after water exposure (not shown here) has revealed the fact that due to photooxidation, the surfaces of the $\mathrm{ZnS}$ nanoparticles get oxidized using the dissolved oxygen in water in the presence of sun light. Oxide leaves the surface as a molecular species $\left(\mathrm{SO}_{2}\right)$, leaving $\mathrm{Zn}$ and a freshly exposed layer of $\mathrm{ZnS}$ behind. Water may dissolve a part of the $\mathrm{SO}_{2}$ released in the process causing reduction in the $\mathrm{pH}$ value of the water (6.3). After the exposure of the nanoparticles in the water, the $\mathrm{Zn} / \mathrm{S}$ ratio is found to raise over that of the stoichiometric value of the freshly prepared samples confirming the loss of $\mathrm{S}$ from the nanoparticles. Surfaces of the nanoparticles of $\mathrm{ZnS}$, exposed to water and light, are thus effectively destroyed by these redox cycles and results in the reduction of the dissolved oxygen content in water. Therefore, the increasing deficiency in dissolved oxygen content with increasing nanoparticle concentration or exposure time can be attributed to the results of traditional toxicity tests as shown in Figures 2, 3, 4, and 5.

Mortality rate is found to be higher for exposure of the zooplanktons to the smaller particles. Also departure from control condition for hopping frequency and heart rate are more found for smaller particles. This observation can be explained by the fact that smaller particle size culminates higher surface to volume ratio of the nanoparticles present in the water. $\mathrm{ZnS}$ nanoparticles having smaller sizes offer greater surface area. This made the particles more sensitive to surface photooxidation process, leading to a faster deficit in dissolved oxygen content compared to the samples having larger particle sizes.

Figure 5 shows a peak for 30 minutes of exposure time for nanoparticles of $3 \mathrm{~nm}$ and $7 \mathrm{~nm}$ indicating the fact that the zooplanktons are producing maximum possible body resistance against the adverse condition produced by the exposure of $\mathrm{ZnS}$ nanoparticles in these conditions.

\section{Conclusion}

Daphnia sp. from Lal Bandh, Bishnupur, (Bankura district), and Saheb Bandh, Purulia (Purulia district), is exposed to $\mathrm{ZnS}$ nanoparticles of different sizes to perform traditional toxicity test. The percentage of mortality is found to increase with increasing nanoparticle concentration or exposure time and saturates for higher concentrations or exposure time. Mortality is found to be higher for smaller particles. Hopping frequency and heart rate were also found to increase with increasing exposure time for a fixed nanoparticle concentration. These observations can be explained on the basis of the enhanced photooxidation property of the $\mathrm{ZnS}$ nanoparticles. The present study will help to understand the impact of $\mathrm{ZnS}$ nanoparticles on aquatic organisms in Bankura and Purulia districts that is hitherto unknown. Understanding the potential impacts of nanoparticles on aquatic environment will help in identifying the most appropriate nanotechnology that will preserve the aquatic environment while also advancing medical and environmental technology.

\section{References}

[1] T. Masciangioli and W. X. Zhang, "Environmental technologies at the nanoscale," Environmental Science and Technology, vol. 37, no. 5, pp. 102A-108A, 2003.

[2] A. N. Shipway, E. Katz, and I. Willner, "Nanoparticle arrays on surfaces for electronic, optical, and sensor applications," ChemPhysChem, vol. 1, no. 1, pp. 18-52, 2000.

[3] B. Nowack and T. D. Bucheli, "Occurrence, behavior and effects of nanoparticles in the environment," Environmental Pollution, vol. 150, no. 1, pp. 5-22, 2007.

[4] E. Y. Krysanov, D. S. Pavlov, T. B. Demidova, and Y. Y. Dgebuadze, "Effect of nanoparticles on aquatic organisms," Biology Bulletin, vol. 37, no. 4, pp. 406-412, 2010.

[5] L. K. Adams, D. Y. Lyon, and P. J. J. Alvarez, "Comparative ecotoxicity of nanoscale $\mathrm{TiO}_{2}, \mathrm{SiO}_{2}$, and $\mathrm{ZnO}$ water suspensions," Water Research, vol. 40, no. 19, pp. 3527-3532, 2006.

[6] D. Warheit and J. Everitt, "Assessing the biological and environmental risks of nanoparticles," in Proceedings of the 43rd Society of Toxicology Annual Meeting, p. 1850, Baltimore, Md, USA, March 2004.

[7] D. B. Warheit, B. R. Laurence, K. L. Reed, D. H. Roach, G. A. M. Reynolds, and T. R. Webb, "Comparative pulmonary toxicity assessment of single-wall carbon nanotubes in rats," Toxicological Sciences, vol. 77, no. 1, pp. 117-125, 2004.

[8] Z. Tong, M. Bischoff, L. Nies, B. Applegate, and R. F. Turco, "Impact of fullerene $\left(\mathrm{C}_{60}\right)$ on a soil microbial community," Environmental Science and Technology, vol. 41, no. 8, pp. 29852991, 2007.

[9] J. Fang, D. Y. Lyon, M. R. Wiesner, J. Dong, and P. J. J. Alvarez, "Effect of a fullerene water suspension on bacterial 
phospholipids and membrane phase behavior," Environmental Science and Technology, vol. 41, no. 7, pp. 2636-2642, 2007.

[10] Y. Zhu, Q. Zhao, Y. Li, X. Cai, and W. Li, “The interaction and toxicity of multi-walled carbon nanotubes with Stylonychia mytilus," Journal of Nanoscience and Nanotechnology, vol. 6, no. 5, pp. 1357-1364, 2006.

[11] C. J. Smith, B. J. Shaw, and R. D. Handy, "Toxicity of single walled carbon nanotubes to rainbow trout, (Oncorhynchus mykiss): respiratory toxicity, organ pathologies, and other physiological effects," Aquatic Toxicology, vol. 82, no. 2, pp. 94-109, 2007.

[12] A. P. Roberts, A. S. Mount, B. Seda et al., "In vivo biomodification of lipid-coated carbon nanotubes by Daphnia magna," Environmental Science and Technology, vol. 41, no. 8, pp. 30283029, 2007.

[13] E. Oberdörster, "Manufactured nanomaterials (fullerenes, $\mathrm{C}_{60}$ ) induce oxidative stress in the brain of juvenile largemouth bass," Environmental Health Perspectives, vol. 112, no. 10, pp. 10581062, 2004.

[14] J. M. Koziara, P. R. Lockman, D. D. Allen, and R. J. Mumper, "In situ blood-brain barrier transport of nanoparticles," Pharmaceutical Research, vol. 20, no. 11, pp. 1772-1778, 2003.

[15] D. Y. Lyon, L. K. Adams, J. C. Falkner, and P. J. J. Alvarez, "Antibacterial activity of fullerene water suspensions: effects of preparation method and particle size," Environmental Science and Technology, vol. 40, no. 14, pp. 4360-4366, 2006.

[16] D. Y. Lyon, J. D. Fortner, C. M. Sayes, V. L. Colvin, and J. B. Hughes, "Bacterial cell association and antimicrobial activity of a $\mathrm{C}_{60}$ water suspension," Environmental Toxicology and Chemistry, vol. 24, no. 11, pp. 2757-2762, 2005.

[17] E. Oberdörster, S. Zhu, T. M. Blickley, P. McClellan-Green, and M. L. Haasch, "Ecotoxicology of carbon-based engineered nanoparticles: effects of fullerene $\left(\mathrm{C}_{60}\right)$ on aquatic organisms," Carbon, vol. 44, no. 6, pp. 1112-1120, 2006.

[18] S. Q. Zhu, E. Oberdörster, and M. L. Haasch, "Toxicity of an engineered nanoparticle (fullerene, $\mathrm{C}_{60}$ ) in two aquatic species, Daphnia and fathead minnow," Marine Environmental Research, vol. 62, no. 1, pp. S5-S9, 2006.

[19] S. B. Lovern and R. Klaper, "Daphnia magna mortality when exposed to titanium dioxide and fullerene $\left(\mathrm{C}_{60}\right)$ nanoparticles," Environmental Toxicology and Chemistry, vol. 25, no. 4, pp.11321137, 2006.

[20] S. J. Yu, Y. G. Yin, and J. F. Liu, "Silver nanoparticles in the environment," Enviornmental Science: Processes and Impacts, vol. 15, no. 1, pp. 78-92, 2013.

[21] I. Sondi and B. Salopek-Sondi, "Silver nanoparticles as antimicrobial agent: a case study on E. coli as a model for gramnegative bacteria," Journal of Colloid and Interface Science, vol. 275, no. 1, pp. 177-182, 2004.

[22] J. R. Morones, J. L. Elechiguerra, A. Camacho et al., "The bactericidal effect of silver nanoparticles," Nanotechnology, vol. 16, no. 10, pp. 2346-2353, 2005.

[23] S. Pal, Y. K. Tak, and J. M. Song, "Does the antibacterial activity of silver nanoparticles depend on the shape of the nanoparticle? A study of the gram-negative bacterium Escherichia coli," Applied and Environmental Microbiology, vol. 73, no. 6, pp. 17121720, 2007.

[24] C. N. Lok, C. M. Ho, R. Chen et al., "Proteomic analysis of the mode of antibacterial action of silver nanoparticles," Journal of Proteome Research, vol. 5, no. 4, pp. 916-924, 2006.
[25] R. J. Griffitt, R. Weil, K. A. Hyndman et al., "Exposure to copper nanoparticles causes gill injury and acute lethality in zebrafish (Danio rerio)," Environmental Science and Technology, vol. 41, no. 23, pp. 8178-8186, 2007.

[26] G. Federici, B. J. Shaw, and R. D. Handy, "Toxicity of titanium dioxide nanoparticles to rainbow trout (Oncorhynchus mykiss): gill injury, oxidative stress, and other physiological effects," Aquatic Toxicology, vol. 84, no. 4, pp. 415-430, 2007.

[27] A. D. Bianchini and C. M. Wood, "Does sulfide or water hardness protect against chronic silver toxicity in Daphnia magna? A critical assessment of the acute-to-chronic toxicity ratio for silver," Ecotoxicology and Environmental Safety, vol. 71, no. 1, pp. 32-40, 2008.

[28] A. . Feswick, R. J. Griffitt, K. Siebein, and D. S. Barber, "Uptake, retention and internalization of quantum dots in Daphnia is influenced by particle surface functionalization," Aquatic Toxicology, vol. 130-131, pp. 210-218, 2013.

[29] C. H. Lu, B. Bhattacharjee, C. H. Hsu, S. Y. Chen, R. C. Ruaan, and W. H. Chang, "Highly luminescent CdSe nanoparticles embedded in silica thin films," Journal of Electroceramics, vol. 17, no. 1, pp. 21-29, 2006. 

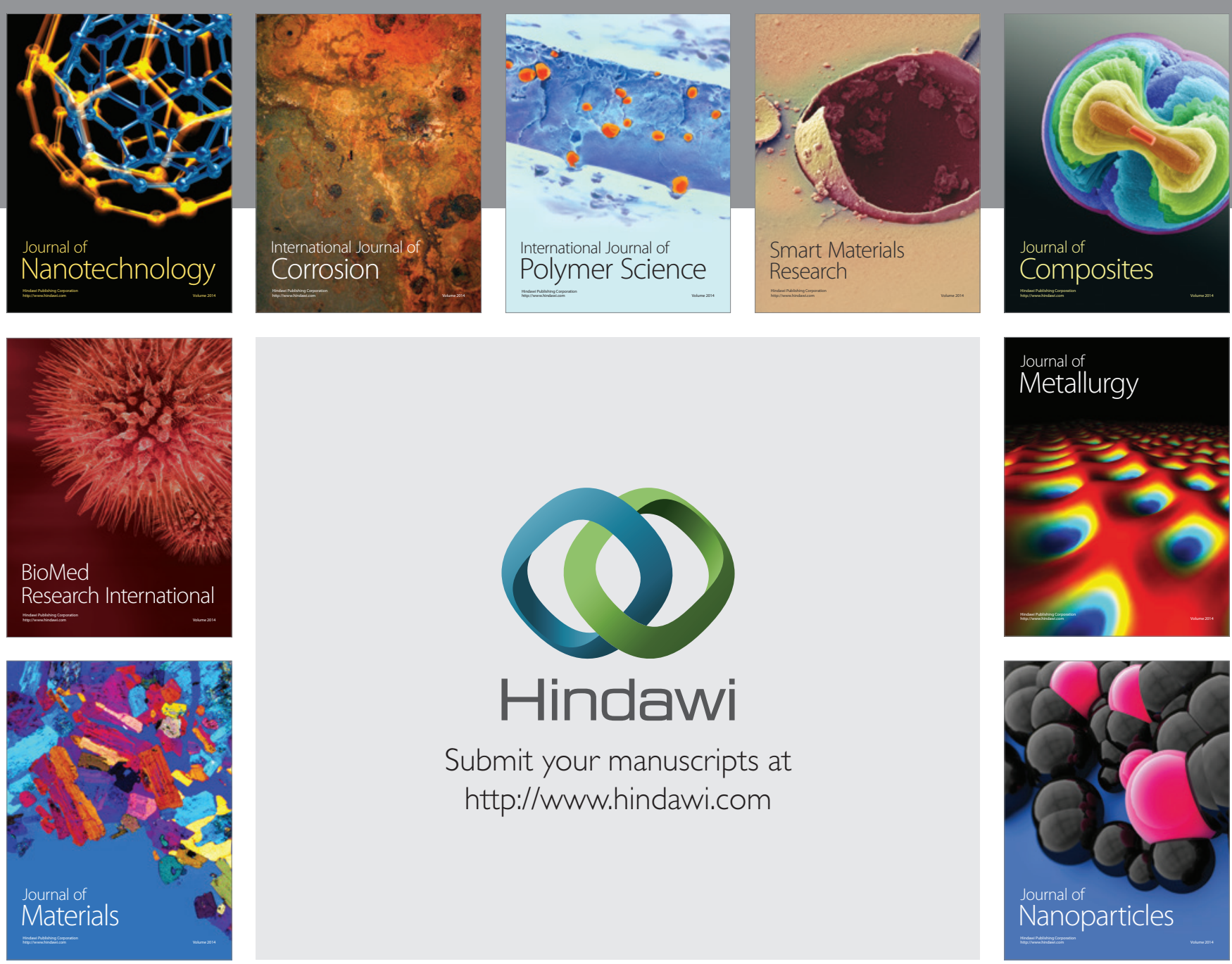

Submit your manuscripts at http://www.hindawi.com
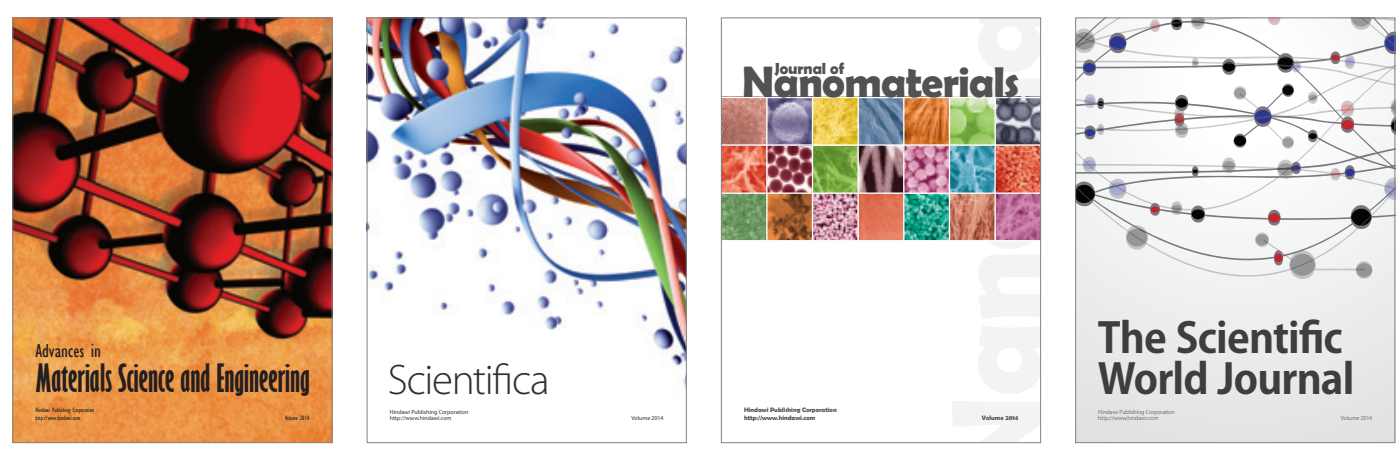

\section{The Scientific World Journal}
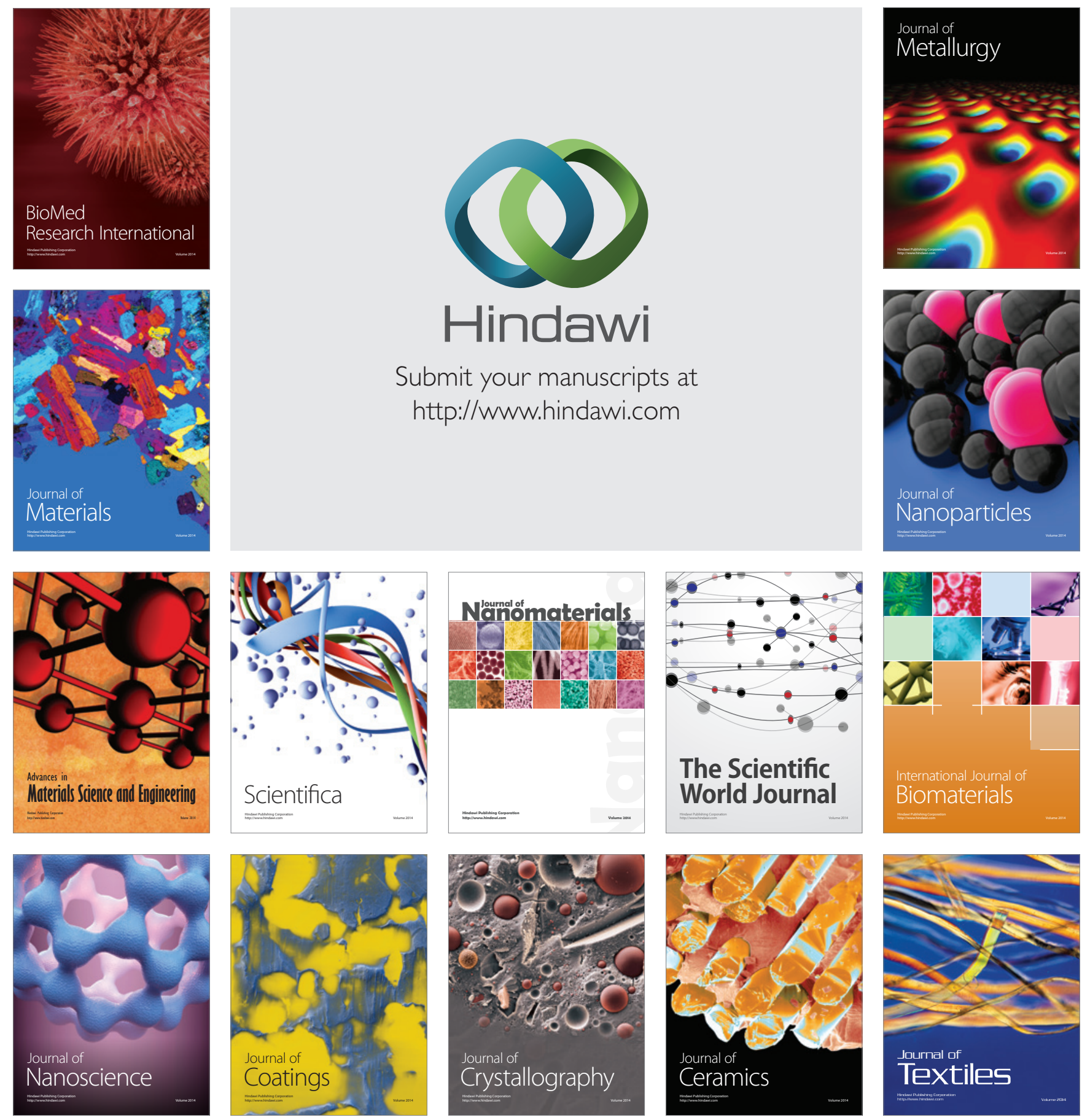